\title{
Ground Improvement: Referees 2021
}

The following is a list of referees who have reviewed papers for Ground Improvement between 17 November 2020 to 17 November 2021.

The Institution of Civil Engineers is very grateful for their assistance.

We are continually looking for suitable reviewers for papers submitted to Ground Improvement. Papers published in ICE journals must be submitted to at least two independent referees to judge accuracy, style, impact, importance and interest.

If you are interested in reviewing articles on any topic related to technological developments, feasibility studies and innovative

Pouyan Abbasi maedeh

Jasim Abd

Costas Anagnostopoulos

Afshin Asadi

Deepankar Ashish

Eyübhan Avci

Mustafa Aytekin

Tadikonda Bharat

Xia Bian

Witold Bogusz

Jinchun Chai

Surya Sarat Chandra Congress

\author{
Nilo Consoli \\ Hamid Gadouri \\ Sara Gargano \\ Jie Han \\ Pitthaya Jamsawang \\ Michael Jefferies \\ Arvind Jha \\ Apiniti Jotisankasa \\ Houssam Khelalfa \\ Masaki Kitazume \\ Junhwan Lee \\ Wentao Li
}

engineering applications for all aspects of ground improvement, ground reinforcement and grouting, please submit your name, qualifications or CV, and areas of expertise. We are in need of individuals who will agree to review papers in a timely fashion (within 3 to 4 weeks of receipt) and provide confidential feedback to the Editorial Advisory Panel concerning the quality of the paper and any suggested revisions that would be appropriate.

If you are such a person, please contact Jaskarn Rai (tel.: +44 (0)207 665 2453; e-mail: jaskarn.rai@icepublishing.com) for more information on the referee process.

\section{Cheng Lin}

Suman Manandhar

Sérgio Marques

James Mcllquham

Bashir Mir

Mehdi Mirzababaei

Naloan Naloan Sampa

Sanjay Nimbalkar

Babalu Rajput

Robinson Retnamony

Paolo Ruggeri

Cholachat Rujikiatkamjorn

\section{Manojit Samanta}

Marina Schnaider Bortolotto Colin Serridge

S Smitha

Amin Soltani

Rama Talat Rashad

Akanksha Tyagi

Panich Voottipruex

Yaolin Yi

Irem Yildirim 